\title{
SER PROFESSOR OU ESTAR PROFESSOR: AS IMPLICAÇÕES NO CONTEXTO DE SALA DE AULA
}

\author{
SER PROFESOR O ESTAR PROFESOR: LAS IMPLICACIONES EN EL \\ CONTEXTO DEL AULA DE CLASE
}

\author{
TO BE A TEACHER OR BEING A TEACHER: THE IMPLICATIONS IN THE \\ CLASSROOM CONTEXT
}

\author{
Joice Ferreira NICOLA ${ }^{1}$ \\ Simone Martins de Caires PALARO ${ }^{2}$ \\ Sebastião de Souza LEMES ${ }^{3}$
}

RESUMO: Em um contexto em que se promove o uso de metodologias ativas, estratégias e planejamentos de aulas aliados à tecnologia, entre outras muitas ferramentas tão significativas para disponibilizar um ambiente propício ao desenvolvimento de um aprendizado eficaz, questiona-se por que nossos alunos não alcançam os objetivos propostos. O que é necessário de fato para que o processo de ensino/aprendizagem seja eficaz e torne o aluno um indivíduo autônomo? O problema talvez não esteja somente no aluno. Será que o professor, mesmo tendo capacitação profissional para atuar na sua área, teve as orientações e a formação acadêmica necessária para trazer aos alunos métodos e ferramentas para as mais amplas possibilidades de melhorarem seu universo do conhecimento? Nesse contexto, esse trabalho tem o objetivo de trazer uma reflexão sobre a formação docente de maneira a atender a demanda no contexto atual da educação, somado ao ato pedagógico que incentive no professor a autonomia que muitas vezes ele deve instigar em seus alunos, mas devido à falta de motivação e atuação do "ser professor" não consegue desenvolver as habilidades que a educação exige.

PALAVRAS-CHAVE: Educação. Professor. Aluno. Aprendizagem. Pedagogia.

RESUMEN: En un contexto en el que se promueve el uso de metodologías activas, estrategias y planificaciones de clases relacionadas a la tecnología, entre otras muchas herramientas tan significativas para disponer un ambiente propicio al desarrollo de un aprendizaje eficaz, se cuestionan por qué nuestros alumnos no logran los objetivos propuestos. ¿Qué es necesario de hecho para que el proceso de enseñanza/aprendizaje sea

${ }^{1}$ Universidade Estadual Paulista (UNESP), Araraquara - SP - Brasil. Aluna Especial no Programa de PósGraduação em Educação Escolar (FCL). Professora de Língua Inglesa do ensino médio e técnico da ETEC. Pedagoga. Especialista em metodologia do ensino da língua inglesa. ORCID: https://orcid.org/0000-0001-6340481X. E-mail: joiceferreiranicola@gmail.com

${ }^{2}$ Universidade Estadual Paulista (UNESP), Araraquara - SP - Brasil. Aluna Especial no Programa de PósGraduação em Educação Escolar (FCL). Professora auxiliar na rede Estadual do Estado de São Paulo. Especialista em educação especial e psicopedagogia. Docente convidada Unisagrado. ORCID: https://orcid.org/0000-0002-3039-7163. E-mail: simonemcp2008@hotmail.com

3 Universidade Estadual Paulista (UNESP), Araraquara - SP - Brasil. Professor no Departamento de Antropologia, Política e Filosofia. Coordenador do Programa de Pós-Graduação em Educação Escolar. Doutorado em Psicologia (USP). ORCID: https://orcid.org/0000-0002-0750-9294. E-mail: ss.lemes@gmail.com

RPGE- Revista on line de Política e Gestão Educacional, Araraquara, v. 25, n. 1, p. 344-366, jan./abr. $2021 . \quad$ e-ISSN:1519-9029. DOI: https://doi.org/10.22633/rpge.v25i1.14937 
eficaz y vuelva el alumno un sujeto autónomo? El problema quizás no esté totalmente en el alumno. Aunque el profesor tenga formación profesional para trabajar en su área, ¿ha tenido la orientación y la formación académica necesaria para aportar a los alumnos métodos y herramientas para las más amplias posibilidades de mejorar su universo de conocimiento? En este contexto, este trabajo pretende aportar una reflexión sobre la formación del profesorado con el fin de satisfacer la demanda en el contexto actual de la educación, sumado al acto pedagógico que fomenta la autonomía del profesor que muchas veces debe instigar en sus alumnos, pero que debido a la falta de motivación y actuación del "ser profesor" no puede desarrollar las competencias que la educación requiere.

PALABRAS CLAVE: Educación. Profesor. Estudiante. Aprendizaje. Pedagogía.

ABSTRACT: In a context where the use of active teaching-learning methodologies, strategies and class planning linked to technology are promoted, among other meaningful tools to dispose a proper environment to develop an efficient learning, questions like why our students do not achieve their goals arise. What is necessary indeed to make the learning process efficient and allow the students to be autonomous in their learning process? The problem may not be only the student. May the teacher even having professional training to act in his/her career be prepared with orientation and academic qualification enough to bring their students methods and tools to develop the most possible improvements in the student's learning universe? In this context, this work aims to bring up a reflection about the teaching training and education in a way to meet the demand in the current educational field, added to the pedagogical act that encourages the teacher's autonomy that he/she has to instigate in his/her students, but due to the lack of motivation and the performance of "Being teacher" cannot develop the skills that education requires.

KEYWORDS: Education. Teacher. Student. Learning. Pedagogy.

\section{Introdução}

No contexto educacional em que estamos vivendo hoje, temos presenciado muitas transformações sociais, políticas, econômicas, culturais e tecnológicas. Questões estas que têm impactado as pessoas como um todo, nas relações de trabalho e de sociedade.

Essas transformações, de acordo com Bauman (2009 apud DIESEL et al., 2017, p. 269), podem ser compreendidas partindo de duas contribuições: a sólida e a líquida. Traduz como líquida, o contraste do atual estágio da humanidade e, sólida, o contraste anterior ao atual. Diz-se sólido o período em que a durabilidade era a lógica e os conhecimentos adquiridos davam suporte à resolução de problemas. Líquida é a condição sócio-histórica em que vivemos, e está caracterizada pela fluidez e incerteza, onde a imprevisibilidade impera. Neste estágio de impermanência situa-se a educação contemporânea, com a escola e todos os que dela dependem. 
Outrossim, entendemos que, em contraponto às experiências pedagógicas sólidas e conteudistas, as atuais demandas exigem do docente uma nova postura em relação ao conhecimento. Seguindo este pensamento, surge então a necessidade de repensar a formação dos professores, tendo como princípio a diversidade dos saberes essenciais à sua prática, valorizando os conhecimentos já construídos e baseando-se numa postura reflexiva, investigativa e crítica.

Quando falamos em saberes construídos, devemos primeiramente nos posicionar sobre a postura do professor não só em questão a sua práxis, como também em relação a ética além da própria questão "ética" visto que ele deve ser equilibrado pois corresponde não só a figura que instiga e fomenta o conhecimento, mas também é de certa forma um influenciador de grande impacto na vida dos alunos.

Em contraponto temos a escola entendida como uma instituição contextualizada onde é refletida a sociedade e a história e o professor é o coadjuvante na criação desse enredo.

Rocha (2014), faz uma referência a Apple (1986), que descreve o professor como um profissional capaz de julgar suas próprias ações. Sendo assim, é preciso dar autonomia e voz a ele, a fim de transpor a técnica para o campo da reflexão, fazendo com que sua prática seja pensada e repensada. Esse professor "prático-reflexivo" vem para superar a rotinização de suas práticas e refletir sobre todo o processo de suas ações. Então, as noções de saber do professor acabam ultrapassando a dicotomia de teoria e prática, tornando-se viável a associação entre a formação e os saberes do professor, mesmo que o caráter políticoideológico encontre empecilhos para sua execução.

Revendo a nossa história, esse pensamento sobre a reflexão da ação docente e do professor mais reflexivo em relação a sua prática, surgiu a partir da década de 80 e, no Brasil, a partir da década de 90, passando a ter a nomenclatura de docência reflexiva que, por sua vez, pressupunha a formação de concepções teóricas para análise da questionável prática dos professores. Desta forma, podemos entender que a formação do professor não se dá em momentos distintos - primeiro a formação teórica e depois a experiência prática - mas sim, no diálogo da prática com a teoria.

Para Rocha (2014), segundo Schön (1992), no que se refere à formação do professor, este:

[...] considera que somente a teoria é insuficiente para orientar a prática docente. Para ele, o professor não deve ser o especialista que aplica conhecimentos, mas um "prático reflexivo", alguém que age e toma decisões a partir da avaliação dos problemas que surgem no decorrer de seu trabalho em sala de aula. Tal prática, no seu entender, deveria ser constantemente

RPGE- Revista on line de Política e Gestão Educacional, Araraquara, v. 25, n. 1, p. 344-366, jan./abr. $2021 . \quad$ e-ISSN:1519-9029. 
reelaborada em função da reflexão sobre a ação, que ocorre antes, durante e depois da atuação do professor junto aos alunos, tendo como objetivo superar as dificuldades vividas no dia a dia.

Dessarte, partindo de toda essa análise realizada nestes escritos, não devemos "estar professor", ou seja, estar somente como um ser humano que se coloca de maneira autoritária e repassa o conhecimento transposto pelos livros didáticos. O "ser professor" ultrapassa muitas barreiras da educação.

Darsie e Carvalho (1996) nos trazem um raciocínio sobre a formação desse professor, onde o mesmo necessita passar pela reflexão do seu saber e do seu saber fazer, pois ambos são indissociáveis, e a mudança de um implica no repensar e no modificar do outro. Ainda propõe a compreensão da metacognição como uma atividade do pensar e do verbalizar o saber, suas semelhanças e diferenças, bem como, o que se está aprendendo, refletindo sempre sobre os procedimentos que nos permitem chegar a esse saber. Analisando alguns autores sobre a formação do professor, a autora distingue entre tantos outros o famoso Shön, que já foi destacado anteriormente por Rocha (2014). Neste, Darsie e Carvalho (1996) destacam a importância de o professor adquirir três conceitos diferentes a fim de integrar o pensamento prático: o conhecimento na ação, a reflexão na ação, e a reflexão sobre-a-ação e sobre a reflexão-na-ação. Esses três conceitos indissociáveis vão constituir o pensamento prático, a fim de enfrentar as situações na prática docente, buscando melhorá-la ou modificá-la, a saber:

[...] a reflexão sobre a aprendizagem do conteúdo a ensinar e sobre a aprendizagem do como ensinar leva o sujeito à tomada de consciência dos seus conhecimentos e à reelaboração desses (DARSIE; CARVALHO, 1996, p. 106).

Assim sendo, o estudante passa a ser um sujeito ativo do processo de aprender, e a aprendizagem deve estar sempre em suas mãos, devendo ser sujeitos conscientes e responsáveis pelo próprio conhecimento. Porém, o professor deve desempenhar a função e execução dos objetivos, sendo ativo nos processos de reflexão crítica, estando preparado para assumir tal posição e tornando-se capaz de pensar e conduzir autonomamente sua tarefa, não se esquecendo da importância de investir em uma formação e uma aprendizagem do futuro docente, de maneira reflexiva, criando alicerces pelo qual será enaltecido: o valor do saber do aprendiz e de como aprender, bem como o valor do saber do professor e de como ensinar.

Para isso, os professores precisam estar preparados para interagir, instigar, mediar e estimular seus alunos, utilizando-se de tecnologias. 
O educador precisa se apropriar dessa aparelhagem tecnológica para se lançar a novos desafios e reflexões sobre sua prática docente e o processo de construção do conhecimento por parte do aluno (FARIA, 2004, p. 4).

Nesse ponto, passamos a socializar, e tal socialização tem uma fundamentação construtivista e muito se traz do ideário Vygotskyano. O professor passa a participar junto com os alunos das interações, pesquisa e construção da aprendizagem e do uso menos frequente do método tradicional de ensino. Ainda, de acordo com a autora,

[...] usar o computador como um simples "quadro-negro" ou um "clicar" de páginas, não geram motivação e nem explora todo potencial desse recurso, além de não ser considerado interativo, mas, sim, reativo (FARIA, 2004, p. 2 , grifo do autor).

Mesmo em um contexto em que se privilegia o uso de tecnologias, temos que tomar cuidado para não transformar as ferramentas que usamos no ensino tradicional, como livro impresso, em livro digital: a ferramenta usada é diferente, com o mesmo conteúdo, porém, em formato diferente. Da mesma forma, vale salientar que por mais interessante que seja a tecnologia, os atores continuam sendo professor e aluno, em conjunto para a construção da aprendizagem.

A tecnologia facilita a transmissão da informação, mas o papel do professor continua sendo fundamental na escolha e correta utilização da tecnologia, dos softwares e seus aplicativos para auxiliar o aluno a resolver problemas e realizar tarefas que exijam raciocínio e reflexão (FARIA, 2004, p. 2).

A educação precisa de uma nova roupagem, novos horizontes e possibilidades de estimular o entusiasmo tanto do professor quanto do aluno. A tecnologia vem para trazer um estímulo diferente do que se tem no ensino tradicional. A aplicação inteligente do computador facilita a passagem do modelo mecanicista para o sociointerativista.

A despeito de um novo paradigma de que a educação depende do projeto político pedagógico da escola, deve também partir do professor um interesse em quebrar os antigos métodos e criar propostas novas. Para que haja uma construção do aprendizado ele deve, ainda, estar motivado e preparado para o uso das tecnologias.

Planejar as aulas com uso de tecnologias requer do professor um pensamento mais amplo do que o usual, visto que ele precisa compreender as habilidades que o aluno tem e quais as habilidades ele deseja trabalhar em determinado conteúdo e ferramentas. Precisa, do mesmo modo, estar preparado para ser o mediador nesse processo, porquanto todos possam ter acesso às tecnologias, o professor ainda será o mediador: aquele que instigará o saber e os 
questionamentos adequados para que possa acontecer a reflexão e a construção do conhecimento.

Essa nova proposta pedagógica precisa ser pensada de forma crítica, já que o professor sai da escola centrado nos conhecimentos onde o mesmo é o "Mestre", com o poder absoluto, e passa a construir, questionar, duvidar, enfrentar desafios junto com os alunos em uma nova proposta professor-aluno-máquina-tecnologia-conteúdo, exigindo do aluno também o preparo necessário para interagir com o recurso computacional.

Inúmeras são as oportunidades de utilizar tecnologia em função do aprendizado, tais como: software de autoria, tutorial, de exercício, prática e até mesmo o uso da televisão em sala de aula. Sabemos que, apesar de mais difundido na atualidade, não podemos deixar de salientar que o ensino com tecnologias no Brasil iniciou-se por volta da década de 70, e desde então vem criando forças.

A adoção da tecnologia traz à tona a questão do ponto de preparação que o aluno tem para utilizar as tecnologias, outra problemática para o professor no momento de seu planejamento.

Em um mundo onde existe a expressão "sociedade do conhecimento", em que a adoção das tecnologias gera um avanço nesse próprio conhecimento, também encontramos a expressão "sociedade da informação", que utiliza da tecnologia para uma rápida atualização e socialização dos conteúdos. Devemos estar dispostos a analisar se estamos preparando nossos alunos para serem autônomos e competentes a fim de desempenhar suas habilidades e competências no mercado de trabalho e, ao mesmo tempo, desenvolverem a auto-organização.

É papel do professor repensar a sua prática constantemente, uma vez que ele deve estar apto ao ensino-aprendizagem, capacitando seus alunos para que possa acontecer essa dinâmica. Deve ser reflexivo, proativo e sempre buscar novas práticas, métodos e tecnologias. $\mathrm{O}$ amor, o desejo de aprender e a busca por um planejamento participativo e interdisciplinar, juntamente com a avaliação constante, cria oportunidades de reequilíbrio permanente e consequentemente um aprendizado maior.

Hodiernamente, com o advento da internet, conseguimos ter acesso ao aprendizado de qualquer lugar, em qualquer hora e sobre qualquer assunto. $\mathrm{O}$ que temos com a tecnologia no momento atual é uma integração de tempos e espaços. Por esse motivo, a educação formal está cada vez mais blended, misturada, híbrida, e o professor, por sua vez, deve seguir acompanhando essa evolução.

As instituições educacionais que ficam atentas às mudanças possuem dois caminhos a escolher: um mais suave, que trata de mudanças progressivas, ou seja, mantém o modelo 
curricular predominante e prioriza o envolvimento do aluno com as metodologias ativas. $\mathrm{O}$ outro caminho, mais profundo, traz modelos inovadores, desafiadores. Modificam o projeto, os espaços físicos, as metodologias, entendendo que cada aluno possui o seu próprio ritmo, mas tudo isso com a supervisão de professores orientadores.

Como já foi visto, as metodologias ativas precisam acompanhar os objetivos pretendidos. Se quisermos alunos proativos, precisamos de metodologias que necessitem do envolvimento deste aluno. Se desejarmos que eles sejam criativos, precisamos incentivar a inciativa através de inúmeros desafios e atividades.

Morán (2015) afirma que podemos fazer mudanças progressivas. Só não podemos manter o modelo tradicional e pensar que com poucos ajustes ficará tudo certo. Esses ajustes, mesmo que progressivos, devem ser profundos, pois o foco é: "aluno ativo e não passivo, envolvimento profundo e não burocrático, professor orientador e não transmissor" (p. 22). Ainda segundo o autor, alguns componentes são fundamentais para o sucesso da aprendizagem: a criação de desafios, atividades e jogos que estimulam as recompensas, combinam percursos pessoais e se inserem em plataformas adaptativas que são essenciais para o desenvolvimento deste aluno. O professor torna-se um articulador, acompanhando, mediando e analisando os percursos realizados por seus alunos.

Em educação - em um período de tantas mudanças e incertezas - não
devemos ser xiitas e defender um único modelo, proposta, caminho.
Trabalhar com modelos flexíveis com desafios, com projetos reais, com
jogos e com informação contextualizada, equilibrando colaboração com a
personalização é o caminho mais significativo hoje, mas pode ser planejado
e desenvolvido de várias formas e em contextos diferentes (MORÁN, 2015,
p. 25).

A Aula Invertida (Flipped class) torna-se um papel fundamental neste processo. Inverte-se a lógica tradicional de que o professor ensina primeiro e o aluno retoma em casa, realizando as tarefas escolares. Nessa inversão, o aluno primeiramente caminha sozinho através de vídeos, leituras e atividades, para depois desenvolver em sala de aula os conhecimentos que ainda não foram possíveis de serem desenvolvidos, com a ajuda dos colegas e a orientação do seu professor.

Essa inversão do modelo tradicional de aula faz com que os alunos acessem vídeos e materiais básicos antes, estudando-os e dando um feedback para os professores através de pequenas avaliações rápidas e corrigidas automaticamente.

O ensinar e o aprender acontecem numa interligação simbiótica, profunda, constante entre o que chamamos mundo físico e mundo digital. Não são dois

RPGE- Revista on line de Política e Gestão Educacional, Araraquara, v. 25, n. 1, p. 344-366, jan./abr. 2021. e-ISSN:1519-9029. 
mundos ou espaços, mas um espaço estendido, uma sala de aula ampliada, que se mescla, hibridiza constantemente (MORÁN, 2015, p. 16).

Defronte dos resultados, o professor planeja quais são os pontos mais relevantes para trabalhar com a sala. Neste caso, o papel do professor passa a ser mais de curador do que de orientador. Curador no sentido de fazer a escolha do que é mais importante, ajudando os alunos a encontrar materiais e atividades disponíveis. Curador no sentido de cuidador, cuidando de cada um, dando apoio, acolhendo, estimulando, valorizando, orientando e inspirando.

Segundo Morán (2015, p. 23),

Um bom professor pode enriquecer materiais prontos com metodologias ativas: pesquisa, aula invertida, integração sala de aula e atividade on line, projetos integradores e jogos. De qualquer forma esses modelos precisam também evoluir para incorporar propostas mais centradas no aluno, na colaboração e personalização.

O ensino híbrido (Blended learning) também se apresenta como uma alternativa de equilíbrio entre a aprendizagem individual e grupal. Morán enfatiza dizendo que na educação acontecem vários tipos de Blended, que é quando integramos várias áreas de conhecimento através de articulações entre os processos mais formais de ensino e aprendizagem com os informais, os chamados on-line.

A qualidade da docência se manifesta no trabalho em grupo com a personalização (incentivar e gerenciar os percursos individuais de cada aluno), com a colaboração entre todos, e ao mesmo tempo, cada um dos envolvidos se comprometendo com o processo do aprendizado a partir dos objetivos propostos.

Deste modo, os projetos pedagógicos inovadores se interlaçam, na organização curricular, no espaço, no tempo e nos projetos que equilibram a comunicação pessoal e colaborativa, na presencial e na on-line.

Quanto ao professor, seguramente, ele tem papel ativo como design de caminhos, de atividades de grupos e individuais, sendo decisivo neste processo e fazendo-se diferente dos demais. Em vista disso, se torna um gestor e orientador, em uma construção mais criativa e empreendedora.

Mesmo tendo várias instituições aderido a estas metodologias, ainda encontramos certa "acomodação, repetindo fórmulas com embalagens mais atraentes, esperando receitas, num mundo que exige criatividade e capacidade de enfrentar desafios mais complexos", afirma Morán (2015, p. 27). 
Depreendemos que algumas dimensões estão ficando claras para a educação formal: o modelo blended, as metodologias ativas e o modelo on-line. O que precisa ao longo dos anos é capacitar professores, coordenadores e alunos para trabalharem com estas metodologias, criando currículos mais flexíveis e com aulas invertidas.

Muitas das instituições educacionais ainda estão no século passado, com uma visão tradicional de ensino, focando mais nos conteúdos tradicionais e básicos. Há uma falta de visão estratégica para os gestores, pois planejar mudanças envolve repensar a educação de uma forma mais flexível e menos burocrática.

Há também um bom número de docentes e gestores que não querem mudar, que se sentem desvalorizados com a perda do papel central como transmissores de informação e que pensam que as metodologias ativas deixam o professor em um plano secundário e que as tecnologias podem tomar o seu lugar (MORÁN, 2015, p. 27).

Enfim, torna-se possível manter "a sala de aula" se adotarmos um projeto inovador, com currículo, gestão competente, metodologias ativas, ambientes atraentes (físicos e digitais), com docentes bem preparados para orientar os alunos a se tornarem protagonistas da aprendizagem. Todos esses processos tornam-se complexos, mas é necessário serem revisados e reorganizados para avançar rumo a uma educação do futuro, pois,

Educação é um projeto de longo prazo, e a credibilidade acadêmica, fundamental. É importante conciliar a qualidade acadêmica com a viabilidade econômica. É possível conciliar quantidade qualidade, focando em flexibilidade e metodologias ativas (MORÁN, 2015, p. 29-30).

Em sua obra, Edgard Morin (2001) enfatiza que a educação do futuro exige o enfrentamento de problemas que, segundo ele mesmo, são ignorados ou esquecidos. Existe uma preocupação para os educadores em como transmitir conhecimentos dentro de uma sociedade hierarquizada e em constante transformação. Torna-se um desafio lidar com os novos saberes que a própria sociedade impõe e definir quais contribuições terão esses novos saberes para a educação do futuro.

São necessárias novas práticas pedagógicas para uma educação transformadora que esteja centrada na condição humana, no desenvolvimento da compreensão, da sensibilidade e da ética, na diversidade cultural, na pluralidade de indivíduos, e que privilegie a construção de um conhecimento de natureza transdisciplinar, envolvendo relações individuosociedade-natureza. Esta é a condição fundamental para a construção de um futuro viável para as gerações presentes e futuras (MORIN, 2001, p. 13). 
O autor evidencia a sociedade contemporânea e as diferentes maneiras de vincular-se ao universo acadêmico de uma forma mais humana, não esquecendo-se dos conhecimentos antigos, modernos e contemporâneos, e nem deixando de lado a tecnologia, que trouxe para o homem desse novo século imensos benefícios para a formação intelectual humana.

As metodologias ativas, em suma, podem ser utilizadas desde o ensino infantil até a Universidade, variando somente de acordo com o conteúdo. Trata-se de uma metodologia muito eficaz, pois além do aprendizado cognitivo, os alunos aprendem comportamentos sociais, como: a empatia, a colaboração, a estabilidade emocional, entre outras.

A escolha da metodologia ativa vai depender sempre do objetivo da aprendizagem, ou seja, do componente curricular e das ferramentas tecnológicas que estiverem ao alcance do professor.

Ao tentar definir quais ferramentas e metodologias ativas que deverão ser usadas, o professor primeiramente definirá quais os objetivos da aprendizagem. Esses objetivos são direcionados aos alunos, ou seja, o que o aluno deverá ser capaz de fazer após o término do conteúdo e das atividades.

As estruturas devem passar por um processo de planejamento, e para tanto é preciso que esteja diretamente relacionado ao conteúdo, procedimentos, atividades, recursos, estratégias, metodologia e avaliação, a serem adotadas por um espaço de tempo.

O educador pode ter expectativas e diretrizes não oficialmente declaradas, mas que serão parte do processo de avaliação, mas é muito importante que os objetivos sejam bem definidos.

Planejar não é uma tarefa simples, mesmo porque o docente não sabe qual o nível de maturidade de seus alunos, e se muitas vezes existe compatibilidade com os objetivos traçados e com a maneira que o ensino será conduzido.

Ao definirmos clara e de forma estruturada os objetivos, considerando a aquisição de conhecimento, as competências e o perfil do discente, essa análise direcionará o processo e a escolha das estratégias, métodos e delimitação dos conteúdos, como serão feitas as avaliações e se a aprendizagem vai ser efetiva.

Desenvolver essa capacidade de abstração e utilização de um conhecimento específico de forma multidisciplinar é um processo que deve ser bem planejado, definido e organizadamente estimulado durante o período de formação (graduação), levando-se em consideração os estilos de aprendizagem (BELCHOT; FREITAS; VASCONCELLOS, 2006 apud FERRAZ; BELCHOT, 2010, p. 2) 
A taxonomia de Bloom é uma ciência que tem como objetivo estruturar de maneira eficiente e analítica o aprendizado, pois oferece estrutura para o desenvolvimento de avaliação e utilização de estratégias diferentes para estimular, avaliar e propiciar o acesso ao conhecimento. Também propõe ao docente que estimule seus alunos de forma estruturada e consciente, visto que ele deve planejar o desenvolvimento de habilidades e competências possibilitando o desenvolvimento integral - desde as habilidades mais simples (fatos) até os conceitos mais complexos.

Os domínios cognitivo, afetivo e psicomotor foram amplamente discutidos pelos autores dessa taxonomia, mas o mais utilizado e trabalhado é o domínio cognitivo. Muitos educadores tomam esse pressuposto teórico para definirem seus planejamentos.

Quanto à taxonomia, vamos falar brevemente como ela pode ser utilizada para planejar o aprendizado de maneira que os discentes construirão seu conhecimento a partir dos objetivos e metodologias propostas. Trouxe uma possibilidade de padronização da linguagem no meio acadêmico; nesse universo, com instrumentos de aprendizagem mais integrada e estruturada, os avanços tecnológicos foram trabalhados e desenvolvidas novas e diferentes ferramentas para favorecer a aprendizagem.

O domínio cognitivo da taxonomia é estruturado em níveis de complexidade conforme as habilidades mencionadas anteriormente, sendo que para adquirir uma nova habilidade pertencente ao próximo nível, o aluno deve ter dominado e atingido a habilidade do nível anterior.

As categorias do nível cognitivo propostas pós 2001 a partir da revisão influenciada por Krathwohl (2002) são: lembrar, entender, aplicar, analisar, sintetizar e criar.

Tais processos são cumulativos, ou seja, caracteriza uma relação de dependência entre os níveis para que haja o desenvolvimento cognitivo efetivo.

A partir da revisão feita por Krathwohl (2002), os princípios foram mantidos: do simples para o complexo; do concreto para o abstrato; foi atribuída mais flexibilidade ao conceito cumulativo, uma vez que:

- Algumas disciplinas requerem processos cognitivos diferenciados;

- Os estilos de aprendizagem possibilitam aprender num estágio mais elevado e depois compreenderem os anteriores;

- O conceito de metacognição abre espaço para alunos transitarem livremente pelas subcategorias, aperfeiçoando o autoaprendizado. 
Com a revisão estrutural da proposta, originou-se um novo modelo de utilização e passou-se a ter como estrutura uma tabela Bidimensional da taxonomia de Bloom. Tal tabela tem como foco estruturar os objetivos educacionais e auxiliar o educador a fazer um planejamento mais adequado às tecnologias e estratégias educacionais.

$\mathrm{Na}$ tabela bidimensional, o conhecimento pertence à coluna vertical, e o processo cognitivo à coluna horizontal; nas células, formadas pela intersecção das dimensões, são inseridos os objetivos. Houve uma manutenção do design original, mas agregou-se a possibilidade de interpolação das categorias quando necessário; a dimensão do conhecimento (conteúdo) e dos processos cognitivos ficou diferenciada, os verbos de ação da taxonomia original podem ser inseridos, mas para descrever como o objetivo será alcançado, escolha das estratégias e tecnologias, deve-se pensar no gerúndio do verbo. A montagem da tabela deve ser pensada a partir da definição dos objetivos específicos da disciplina e a partir daí criar as categorias de desenvolvimento do aprendizado de forma construtiva.

Tabela 1 - Tabela bidemensional

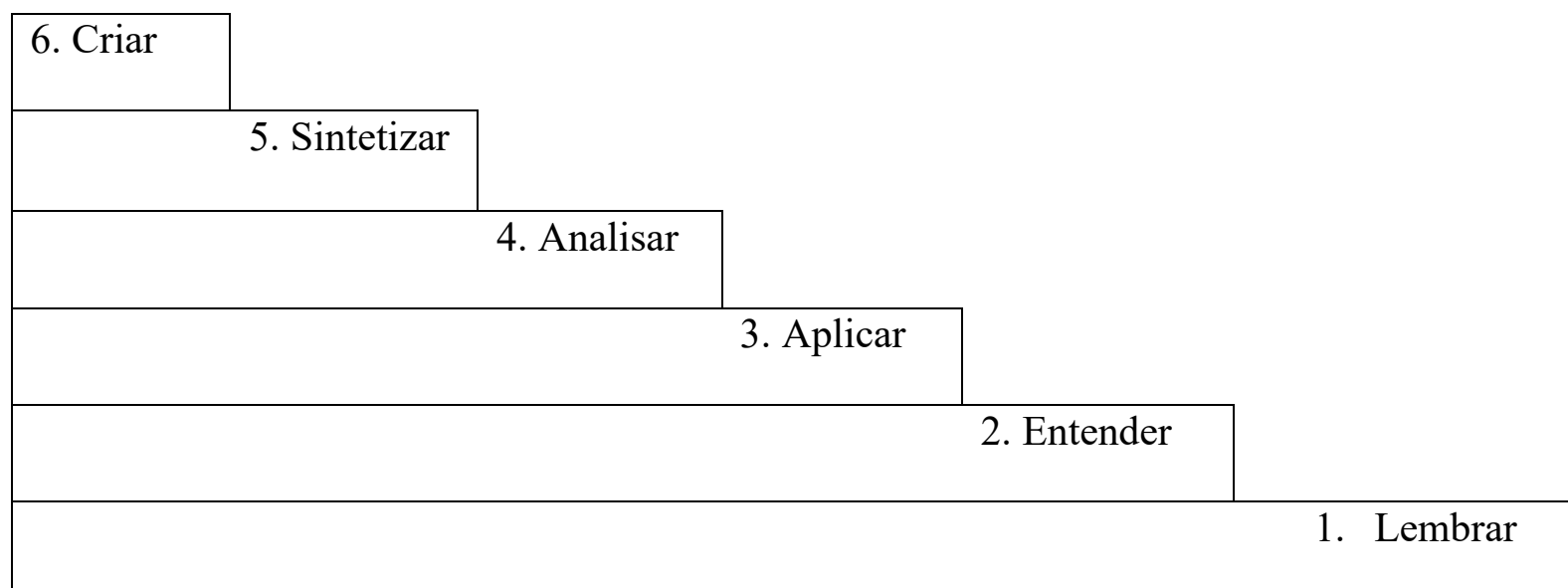

Fonte: Ferraz e Belhot (2010) - adaptado pelas autoras

Categorização atual da Taxonomia de Bloom proposta por Anderson, Krathwohl e Airasian, no ano de 2001.

Essa atualização permitiu um novo olhar, provendo um novo direcionamento nos planejamentos, melhor definição de objetivos instrucionais e direção mais clara, precisa e concisa, de forma a efetivar o processo de ensino aprendizagem e se tornar um aliado aos docentes para promover realmente um aprendizado duradouro e mais efetivo.

Quando se é professor, não se pode pensar que é o "dono" do conhecimento e que está num patamar superior. Para praticar o ato de ensinar é necessário que se leve em conta o saber do educando, sabendo respeitá-lo, que pratique sua fala promovendo gestos e não exigindo 
que se articule o que se fala e não o que se faz. O educador deve promover a criticidade nos educandos e não apenas transferir dados que não façam sentido a eles.

Ele deve pesquisar, mas não somente em sua área de atuação, e sim dentro do contexto dos alunos para promover neles uma reflexão crítica sobre a prática. É importante perceber a identidade cultural, respeitá-la, porém não é necessário que se faça dela a sua verdade.

Ensinar exige reconhecer a autonomia do educando e respeitá-la com bom senso, uma vez que,

Saber que ensinar não é transferir conhecimento, mas criar as possibilidades para a sua própria produção ou a sua construção. Quando entro em uma sala de aula devo estar sendo um ser aberto a indagações, à curiosidade, às perguntas dos alunos, a suas inibições, um ser crítico e inquiridor, inquieto em face da tarefa que tenho - a ele ensinar e não a de transferir conhecimento (FREIRE, 2002, p. 27).

Mas também se deve atentar que suas atitudes marcam positiva ou negativamente o educando. Por isso a importância de se valorizar enquanto profissional, mesmo que essa valorização não seja dada pelos órgãos governamentais.

Ao mesmo tempo em que se ensina se aprende. E todos acabam não permanecendo acomodados; passam de seres ouvintes a interventivos. E esse é o objetivo de se ensinar. É praticar o conhecimento que foi aprendido de maneira crítica, significativa.

O fundamental é que professor e alunos saibam que a postura deles, do professor e dos alunos, é dialógica, aberta, curiosa, indagadora e não apassivada, enquanto fala ou enquanto ouve. O que importa é que professor e alunos se assumam epistemologicamente curiosos. Neste sentido, o bom professor é o que consegue, enquanto fala trazer o aluno até a intimidade do movimento de seu pensamento. Sua aula é assim um desafio e não uma "cantiga de ninar". Seus alunos cansam, não dormem. Cansam porque acompanham as idas e vindas de seu pensamento, surpreendem suas pausas, suas dúvidas, suas incertezas (FREIRE, 2002, p. 52).

De certo, é preciso saber como trabalhar com o educando. Saber que não é necessário somente o conhecimento em suas diversas formas, mas sim humildade para trabalhar com simplicidade, sabendo promover criticidade e construção significativa do conhecimento nesse aluno.

Rocha (2014) nos apresenta uma reflexão bastante instigadora ao citar Apple (1986), pois relata que o professor é um profissional capaz de julgar suas próprias ações e, neste caso, é preciso dar autonomia e voz a ele, sendo de extrema importância transpor a técnica para o campo da reflexão, visto que deve ser uma prática pensada e repensada. O professor "prático 
reflexivo" vai superar a rotinização de suas práticas e refletir sobre todo o processo de sua práxis.

[...] o professor não deve ser o especialista que aplica conhecimentos, mas um "prático reflexivo", alguém que age e toma decisões a partir da avaliação dos problemas que surgem no decorrer de seu trabalho em sala de aula (ALMEIDA, 2001, p. 4 apud ROCHA, 2014, p. 124).

As noções de saber do professor ultrapassam a dicotomia de teoria e prática, tornandose assim viável a associação entre a formação e os saberes do professor, mesmo que o caráter político-ideológico encontre empecilhos para sua execução.

Com efeito, é ainda muito comum a influência do método tradicional de ensino, centrado no docente e na transmissão de conteúdos, em que os estudantes mantem uma postura passiva, apenas recebendo e memorizando as informações numa atitude de reprodução (DIESEL et al., 2017, p. 270).

Temos visto que, mesmo com a tecnologia incluída em sala de aula, o cenário de insatisfação dos alunos continua o mesmo, pois, mudaram-se as ferramentas, mas não se mudou a didática da maneira de atuar.

Com base nisto, como já explicamos anteriormente, o planejamento e a organização de situações de aprendizagem deverão ter o foco nas atividades dos alunos, uma vez que o objetivo principal desta ação educativa é a aprendizagem destes. Desta maneira, há a necessidade de os docentes buscarem novas metodologias de ensino que foquem no protagonismo dos alunos, favorecendo a motivação e promovendo a autonomia deles.

Podemos dizer então que a metodologia ativa, ou melhor, o método ativo, é um processo que visa estimular a autoaprendizagem e a curiosidade do aluno em pesquisar, refletir e analisar as suas possíveis tomadas de decisão, tornando o docente um facilitador deste processo. Sendo assim, podemos pressupor que toda metodologia de ensino e de aprendizagem parte de como o individuo aprende. Então, faz-se necessário uma reflexão a fim de ressignificar a prática docente.

A fim de compreender como isso historicamente sucedeu-se, temos que entender algumas abordagens teóricas.

$\mathrm{Na}$ construção da metodologia da Escola Nova, a atividade e o interesse do aluno foram valorizados. Dewey teve grande influência nessa ideia ao defender que a aprendizagem do aluno ocorre pela ação, colocando-o no centro dos processos de ensino e aprendizagem.

Dentro dos princípios que constituem esta metodologia ativa de ensino, temos como primeiro foco: 
1. O aluno como centro do processo de ensino aprendizagem: primeiramente buscamos a prática e, a partir dela, buscamos a teoria, ou seja, nesta, há uma mudança do “ensinar" para o "aprender", desviando-se o foco do docente para o discente, que assume a responsabilidade pelo seu próprio aprendizado. Passa então a ter controle sobre suas ações dentro da sala de aula, como: pesquisas, leituras, comparação, imaginação, classificação, críticas, busca de suposições, planejamentos de projetos etc.

2. Autonomia: faz com que o aluno assuma uma postura ativa, exercitando uma atitude crítica e construtiva, buscando uma postura autônoma.

Diesel et al. (2017) retratam que a perspectiva de Freire (2015) coincide com essa abordagem dos métodos ativos. Segundo esse educador, um dos grandes problemas da educação estaria no fato de os alunos não serem estimulados a pensar autonomamente.

O professor contribui muito para promover as metodologias ativas em sala de aula. Contribui quando, em seu planejamento, a teorização deixa de ser o ponto de partida e passa a ser o ponto de chegada para a aprendizagem.

3. A problematização da realidade e a reflexão: embora pareçam duas coisas distintas, são completamente indissociáveis.

Dentro do contexto da sala de aula, problematizar significa levantar uma análise sobre a realidade para tomar consciência dela. À medida que o aluno se torna capaz de fazer essa análise, tornando-se protagonista, ele consegue interagir com o conteúdo, ouvindo, falando, perguntando e discutindo. Isto trará diferentes habilidades, como refletir, observar, comparar, inferir, entre tantas outras.

\begin{abstract}
Nesse mesmo viés, Schön (1995) considera que um professor reflexivo deve ter um olhar atento para o seu aluno. Mais do que isso, precisa deixar seu aluno expressar-se e planejar sua aula com base no conhecimento tácito expresso pelo aprendiz. O referido autor considera que a prática pedagógica norteada pela reflexão-na-ação do professor que dá razão ao aluno é dividida em momentos: inicialmente, esse professor permite surpreender-se pelo aluno; na sequência, reflete sobre esse fato e procura compreender as implicações em que envolvem o aspecto levantado pelo aluno; a partir daí, terá condições de reformular o problema; e, por fim, coloca em prática uma nova proposta (DIESEL et al., 2017, p. 279).
\end{abstract}

Paulo Freire (1921-1997), segundo as autoras, em seu discurso sobre Pedagogia Problematizadora, parte do argumento de que educador e educando aprendem juntos através de uma relação dinâmica, onde a prática é orientada pela teoria, viabilizando a reflexão crítica do aluno e o desenvolvimento de sua própria autonomia. 
4. O trabalho em equipe: favorece a interação com os próprios estudantes à medida que temos como ponto de partida a prática social do individuo, tornando-se um elemento de mobilização para a construção daquele mesmo conhecimento. Este movimento de interação leva estudantes e professores a refletir, emitir e argumentar, tanto a favor quanto contra determinada situação.

5. Inovação: parte do princípio de que tanto professor quanto aluno devem inovar as metodologias, renovando-as, inventando ou criando metodologias, ousando para inovar no contexto educacional.

6. Cabe ao professor como mediador, facilitador e ativador: ensinar a pensar de maneira ativa, provocando, desafiando e promovendo condições para que seus alunos construam, reflitam, compreendam e transformem, sem perder de vista o respeito à autonomia e dignidade, refletindo a postura do professor dentro de uma abordagem de metodologias ativas. Este mesmo professor deve assumir uma postura investigativa de sua própria prática, refletindo sobre isso a fim de reconhecer problemas e propor soluções.

Baseando-se em todas as ideias desenvolvidas anteriormente, as autoras levantam os fundamentos teóricos que embasaram a grande dimensão desta abordagem, um fator importantíssimo para nosso entendimento.

As contribuições do interacionismo, diferentemente do inatismo e do behaviorismo, tem no aluno um sujeito ativo que, para se apropriar dos seus conhecimentos, apropria-se dos conteúdos fornecidos pelos docentes, pelos livros didáticos e pelas atividades desenvolvidas em sala de aula. Nesta abordagem, cabe ao professor propiciar a seus alunos o ambiente e os meios necessários à sua aprendizagem. Deve favorecer um ambiente afetivo, dando espaço para que o aluno seja ouvido, sugerindo estratégias e recomendando leituras.

As principais personalidades dessa corrente teórica são: Jean Piaget e Lev Vygotsky. O primeiro desenvolveu um olhar sobre as etapas do desenvolvimento cognitivo, e o segundo levou em consideração a interação dos elementos professor e aluno, concebendo uma perspectiva mais social.

Para Vygotsky, o professor deve partir do princípio de que seu aluno já conhece e domina o conteúdo, para então, interferir e atuar na ZDP (Zona de Desenvolvimento Proximal), levando o indivíduo a alcançar novas aprendizagens através da mediação. Manifestando em outras palavras:

$\mathrm{Na}$ concepção de Vygotsky, a interação social é fundamental para o desenvolvimento cognitivo do indivíduo, por provocar constantemente novas aprendizagens a partir da solução de problemas sob a orientação ou 
colaboração de crianças ou adultos mais experientes. Vygotsky considera que a aprendizagem ocorre dentro da zona de desenvolvimento proximal, que é a distância entre o nível de desenvolvimento cognitivo real do indivíduo (capacidade de resolver problemas independentemente) e o nível de desenvolvimento potencial (capacidade de resolução de problemas sob orientação de um adulto) (MOREIRA, 2011b). Assim, o professor deve levar em conta o conhecimento real da criança e, a partir disso, provocar novas aprendizagens, as quais, quando tornarem-se conhecimento real, novamente propulsionarão outras aprendizagens (DIESEL et al., 2017, p. 281).

Na pedagogia de John Dewey citado por Diesel, quando a criança vai para a escola, não há separação entre vida e educação, desse modo, a educação torna-se uma contínua reconstrução de experiência. A escola, segundo ele, deve proporcionar momentos de aprendizagem que façam sentido para o aluno, apresentando circunstâncias para que suas experiências sejam idênticas às condições de vida do estudante.

Com isso, de acordo com o pensamento de Dewey (1978), é permitido ao estudante compreender os objetos, os acontecimentos e os atos do seu contexto social, habilitando-os para uma participação ativa nas atividades. $\mathrm{O}$ autor define cinco condições para uma aprendizagem que integra diretamente a vida. [...] só se aprende o que se pratica; mas não basta praticar, é preciso haver reconstrução consciente da experiência; aprende-se por associação; não se aprende nunca uma coisa só; toda aprendizagem deve ser integrada à vida (DIESEL et al., 2017, p. 282).

As metodologias ativas favorecem a aprendizagem significativa porque ela não se torna mecânica. A aprendizagem mecânica é aquela onde o aluno decora fórmulas, macetes, leis etc. Após a avaliação, ele não se lembra mais. A corrente teórica de Ausubel trata das condições da ocorrência dessa aprendizagem significativa, ou seja, a não arbitrariedade do material, a subjetividade e a disponibilidade para a aprendizagem. Dessa forma, o docente precisa levar em consideração o conhecimento prévio do aluno, a potencialidade do material utilizado e a disposição do aluno em aprender.

Segundo Freire (2015 apud DIESEL et al., 2017, p. 274), "um dos grandes problemas da educação paira no fato de os alunos serem estimulados a pensarem autonomamente". Sua abordagem construtivista faz do professor o responsável por desenvolver o respeito pelos outros e a capacidade de dialogar.

Segundo as autoras destes pensamentos e teorias explicitadas, podemos tirar várias conclusões: desde aquela em que os professores insistem em continuar com suas aulas monótonas e cansativas, construindo um conhecimento mecânico, até aquelas em que o educador coloca seu aluno como o centro das atenções, constituindo uma aprendizagem significativa, pautada nas metodologias ativas. 
Nesse sentido, a (re)significação da sala de aula, enquanto espaço de interações entre os sujeitos históricos e o conhecimento, o debate, a curiosidade, o questionamento, a dúvida, a proposição e a assunção de posição resultam, sem dúvida, em protagonismo e em desenvolvimento da autonomia (DIESEL et al., 2017, p. 285).

Para um bom professor reflexivo, segundo Darsie e Carvalho (1996), deve haver a compreensão da metacognição, que é a atividade de pensar e verbalizar o que sabemos, as semelhanças e diferenças entre esse saber e o que se está aprendendo e os procedimentos que nos permitem chegar a esse saber.

Para tanto, propõe alguns tópicos:

1. Reflexão e formação do professor: remete à necessidade de formar professores práticos reflexivos, ressaltando o valor da reflexão sobre e na prática.

Nas escolas de formação o professor adquire os conhecimentos historicamente construídos e é conduzido a produtor de saber e de saber fazer.

Segundo Schön (1992 apud ROCHA, 2014), o professor como prático reflexivo distingue três conceitos diferentes que integram o pensamento prático:

a) O conhecimento-na-ação: é o que orienta a atividade humana e se manifesta no saber fazer e saber o que se faz. De acordo com a autora,

Para Nóvoa (1992) as escolas de formação inicial devem ser um lugar de aquisição de conhecimentos, onde os professores são preparados para a difusão dos conhecimentos historicamente construídos, mas são também "um lugar de reflexão sobre as práticas, o que permite vislumbrar uma perspectiva dos professores como profissionais produtores de saber e de saber fazer (DARSIE; CARVALHO, 1996, p. 92).

b) A reflexão-na-ação: representa a atitude de pensar sobre o que fizemos ao mesmo tempo em que realizamos determinada ação. É o melhor instrumento de aprendizagem segundo Perez Gómez (1992): no contato com a prática não só construímos novas teorias, esquemas, mas também se aprende o próprio processo dialético da aprendizagem.

c) A reflexão sobre a ação e sobre a reflexão na ação: Schön (1992 apud ROCHA 2014), é a análise que se realiza a posteriori sobre as características e processos da sua própria ação.

Esses são três componentes indissociáveis para constituir o pensamento prático pois, com isso, ele pode enfrentar as situações da prática, buscando melhorá-la ou modificá-la. 
2. Reflexão distanciada: é o pensar sobre os próprios procedimentos ou atividades intelectuais. O sujeito é levado a lançar um olhar sobre o que ele fez ou aprendeu. Esse tipo de olhar faz com que possamos criticar e reelaborar nosso conhecimento. É tomar consciência do que sabe e do que não sabe, bem como refletir sobre a própria aprendizagem e o que está alterando.

É a tomada de conhecimento do próprio conhecimento, tanto teórico como prático, levando a uma crítica e direcionando todos os envolvidos a refletir, repensar, reelaborar e estabelecer confronto entre o conhecimento prévio e a nova aprendizagem, levando a uma nova construção do conhecimento, compreendendo o objeto de forma diferente da qual se via antes.

A reflexão favorece uma conexão entre o contexto da sala de aula e a vida pessoal, ou seja, torna-se possível a reflexão sobre a aprendizagem e o ensino ao mesmo tempo que analisamos a prática de outros professores, comparados a si próprio.

[...] a reflexão sobre a aprendizagem do conteúdo a ensinar e sobre a aprendizagem do como ensinar leva o sujeito à tomada de consciência dos seus conhecimentos e à reelaboração desses (DARSIE; CARVALHO, 1996, p. 106).

3. Reflexões sobre a Prática na formação inicial: a reflexão traz à discussão a atenção as suas experiências escolares passadas, experiências na aprendizagem da vida pessoal. Isso se torna muito importante pois pode trazer uma avaliação do processo de ensinar e aprender.

A consciência e reflexão das experiências de vida e sobre sua aprendizagem traz um novo modelo de ensino que leva à reflexão e crítica ao velho modelo de ensino.

Sendo assim, os alunos-professores aprendem não só os conteúdos iniciais, mas também aprendem a ensinar, a partir das reflexões sobre as experiências vividas.

4. Diferenciação pedagógica: O trabalho reflexivo é condizente com a diferenciação pedagógica, visto que os alunos-professores são levados a refletir sobre suas práticas, experiências, e a partir dessa reflexão podem trabalhar o seu saber e o saber fazer.

5. Desencadeando a reflexão: nesse tópico a autora traz a reflexão sobre a atividade chamada de reflexão distanciada, que se propõe a utilização de diários com registros das aulas cotidianas dos professores. Esses diários têm como propósito:

a) Acompanhar o processo de aprendizagem, coletando informações;

b) Possibilitar uma tomada de consciência do próprio processo de aprendizagem. 
Sendo assim, a partir dos registros, os alunos-professores podem exercer uma observação e reflexão sobre suas práticas dentro de um novo modelo de ensino; a partir desse processo, também foi possível fazer reflexões sobre as próprias práticas e compará-las com as práticas dos professores que tiveram durante sua vida escolar, tendo uma visão críticoconstrutiva do ensino que se pretende.

Por fim, com o propósito de encerrar todas essas reflexões, Darsie e Carvalho (1996) nos trazem o pensamento de que o estudante é um sujeito ativo do processo de aprender, e que a aprendizagem deve estar em suas mãos, devemos ser sujeitos conscientes e responsáveis pelo nosso conhecimento, porém o professor deve desempenhar a função e execução dos objetivos ativos nos processos de reflexão crítica.

Deve estar preparado para assumir tal posição e ser capaz de pensar e conduzir autonomamente sua tarefa.

Elas também ressaltam que a importância de investir em uma formação e aprendizagem do futuro professor de maneira reflexiva cria alicerces como o valor do saber do aprendiz e como aprender e o valor do saber do professor de como ensinar.

\section{Considerações finais}

Com o intuito de encerrarmos nossa discussão e reflexão, fazemos uma indagação: Estamos e devemos Ser ou Estar professor?

Diante de mais esse raciocínio, Rampineli (2001) traz a reflexão sobre a ética nos diferentes âmbitos da sociedade e apresenta o foco para o professor, indagando se o professor tem o valor da ética em sua profissão, assim como em outras profissões que possuem inclusive um código de ética. Ela traz como resposta que não há códigos de ética para o professor, mas que a profissão de educar exige uma postura ética por parte de todos os envolvidos uma vez que os professores são "modelos". A autora também apresenta uma reflexão sobre a postura do professor em relação aos companheiros de profissão. Segundo ela, sua função ética deve pautar elogios e trazer aos alunos análises positivas de seus colegas de trabalho, não cabendo ao professor fazer críticas de outros colegas pois cria uma situação desfavorável para o ensino das diferentes disciplinas. Além de ser ético em relação as informações que a direção e o corpo docente tratam, não há necessidade de tais informações ultrapassarem o ambiente da sala dos professores/direção.

A ética propõe princípios para a práxis, mas vivemos num mundo complexo que exige uma gama de éticas. Na escola, por exemplo, o professor tem o compromisso de ser o modelo 
para seus discentes trabalhando a justiça, a formação do indivíduo, inspirando através de suas ações e atitudes as gerações que estão em desenvolvimento, com a comunidade escolar e com a sociedade.

O professor deve ser moderado, sóbrio e equilibrado nos setores de sua vida, visto que ele é o representante da família na escola, e que em alguns momentos os próprios pais dos alunos não conseguem dar uma educação socioeconômico-cultural que os filhos deveriam receber em casa; é na escola que o professor exercerá influência na vida dos alunos. Portanto, ele deve constantemente analisar sua postura, comportamentos e apresentação, uma vez que ele é o sinônimo de confiança para todos os envolvidos no âmbito escolar.

A escola é uma instituição contextualizada que figura a sociedade e a história das gerações e o professor, em relação a escola, também é condicionante e condicionado pois suas atitudes e ações influenciam a escola. O contrário também é válido.

$\mathrm{Na}$ sequência, vemos também que a postura do professor em relação a amizade e simpatia com o corpo discente traz aspectos e influências positivas para o desenvolvimento de suas atividades.

O professor deve ser empático, motivador, cultivar relações saudáveis para o aprendizado dos alunos e sempre trabalhar com igualdade entre todos.

Enfatizar a união entre todos, não deve transparecer suas opiniões ou incentivar preconceitos, e sim, ter uma visão partidária neutra, não apresentando palavras que não sejam adequadas ao ambiente escolar, muito menos fazer da sala de aula um local de fuxicos e fofocas sobre as notas, vida e problemas relacionados aos seus alunos.

A responsabilidade de um professor é muito grande perante a sociedade, pois ele é um agente influenciador, e por isso ele deve ter convicção de sua autodefinição. É sua obrigação preparar um plano de curso com todas as possibilidades de explorar e aflorar o melhor conhecimento para seu aluno, além disso, também deve se atualizar constantemente para poder trazer inovações em sua disciplina e estar a par das estratégias didáticas que circundam a sociedade.

O bom professor é autocrítico, tem maturidade, equilíbrio, ousadia e senso crítico, pois frequentemente ele repensa sua práxis, suas metodologias para desenvolver da melhor maneira possível o progresso do ensino dos seus discentes.

Dessa forma, "Ser" professor não é apenas uma profissão, ele deve ter características além de profissionais para desenvolver sua profissão com maestria. Deve ser motivador, animador, ter visão de futuro, ser um bom provocador e desafiador, ético, e ter em mente que a sua ação ajuda a moldar futuras gerações e que depende desse perfil para trazer o melhor 
que o aluno pode dar, sempre com empatia, amizade e compreendendo os limites e os horizontes que pode ajudar o aluno a alcançar.

AGRADECIMENTOS: Ao nosso estimado professor Dr. Sebastião Souza Lemes por nos instigar a desenvolver uma reflexão sobre a temática e por nos inspirar. O mais sincero agradecimento por auxiliar-nos com toda sua bagagem profissional. A você nossa admiração.

\section{REFERÊNCIAS}

DARSIE, M. M. P.; CARVALHO, A. M. P. O início da formação do professor reflexivo. Revista da Faculdade de Educação, São Paulo, v. 22, n. 2, p. 90-108, 1996.

DIESEL, A. et al. Os princípios das metodologias ativas de ensino: uma abordagem teórica. Revista Thema, Pelotas, v. 14, n. 1, p. 268-288, 2017.

FARIA, E. T. O professor e as novas tecnologias. Ser professor, v. 4, p. 57-72, 2004.

FERRAZ, A. P. C. M.; BELHOT, R. V. Taxonomia de Bloom: revisão teórica e apresentação das adequações do instrumento para definição de objetivos instrucionais. Gest. Prod., São Carlos, v. 17, n. 2, p. 421-431, 2010. DOI: https://doi.org/10.1590/S0104530X2010000200015

FREIRE, P. Pedagogia da autonomia: saberes necessários à prática educativa. São Paulo: Paz e Terra, 2002. 92 p.

KRATHWOHL, D. R. A revision of Bloom's taxonomy: an overview. Theory in Practice, v. 41, n. 4, p. 212-218, 2002.

MORÁN, J. Mudando a educação com metodologias ativas. Coleção mídias contemporâneas, convergências midiáticas, educação e cidadania: aproximações jovens, v. 2, n. 1, p. 15-33, 2015.

MORIN, E. Os sete saberes necessários à educação do futuro. 3. ed. São Paulo: Cortez, Brasília, 2001.

PEREZ GÓMEZ, A. O pensamento prático do professor: a formação do professor como prático reflexivo. In: NÓVOA. A. (Coord.). Os professores e sua formação. Lisboa: Dom Quixote, 1992. p. 93-114.

RAMPINELI, E. F. Ser ou estar professor? A construção da ética no contexto escolar.

Revista Linhas, Florianópolis, v. 2, n. 1, 2001.

ROCHA, T. L. Da racionalidade técnica ao professor reflexivo. Cadernos da FUCAMP, v. 13, n. 18, p. 119-127, 2014. Disponível em:

http://www.fucamp.edu.br/editora/index.php/cadernos/article/download/407/306. Acesso em: 15 mar. 2021. 


\section{Como referenciar este artigo}

NICOLA, J. F; PALARO, S. M. C.; LEMES, S. S. Ser professor ou estar professor: as implicações no contexto de sala de aula. Revista on line de Política e Gestão Educacional, Araraquara, v. 25, n. 1, p. 344-366, jan./abr. 2021. e-ISSN:1519-9029. DOI: https://doi.org/10.22633/rpge.v25i1.14937

Submetido em: 25/11/2020

Revisões requeridas em: $28 / 11 / 2020$

Aprovado em: 28/12/2020

Publicado em: 02/01/2021 